\title{
COVID-19 Associated Pulmonary Aspergillosis: Diagnostic Performance, Fungal Epidemiology and Antifungal Susceptibility
}

Nina Lackner ${ }^{1}$, Claudius Thomé ${ }^{2}$, Dietmar Öfner ${ }^{3} \mathbb{D}$, Michael Joannidis ${ }^{4} \mathbb{D}$, Timo Mayerhöfer ${ }^{4} \mathbb{D}$, Rohit Arora ${ }^{5}$, Eldina Samardzic ${ }^{1}\left(\mathbb{D}\right.$, Wilfried Posch ${ }^{1} \mathbb{D}$, Robert Breitkopf ${ }^{6}$ and Cornelia Lass-Flörl ${ }^{1, *(\mathbb{D}}$

1 Institute of Hygiene and Medical Microbiology, Medical University Innsbruck, A-6020 Innsbruck, Austria; nina.lackner@i-med.ac.at (N.L.); eldina.samardzic@i-med.ac.at (E.S.); wilfried.posch@i-med.ac.at (W.P.)

2 Department of Neurosurgery, Medical University Innsbruck, A-6020 Innsbruck, Austria; claudius.thome@i-med.ac.at

3 Department of Visceral, Transplant and Thoracic Surgery, Medical University of Innsbruck, A-6020 Innsbruck, Austria; dietmar.oefner@i-med.ac.at

4 Department of Internal Medicine, Division of Intensive Care and Emergency Medicine, Medical University Innsbruck, A-6020 Innsbruck, Austria; michael.joannidis@i-med.ac.at (M.J.); timo.mayerhoefer@i-med.ac.at (T.M.)

5 Department of Trauma Surgery and Sports Medicine, Medical University Innsbruck, A-6020 Innsbruck, Austria; rohit.arora@i-med.ac.at

6 Department of Anaesthesia and Intensive Care, Medical University Innsbruck, A-6020 Innsbruck, Austria; robert.breitkopf@tirol-kliniken.at

* Correspondence: cornelia.lass-floerl@i-med.ac.at

\section{check for}

updates

Citation: Lackner, N.; Thomé, C.;

Öfner, D.; Joannidis, M.; Mayerhöfer,

T.; Arora, R.; Samardzic, E.; Posch, W.;

Breitkopf, R.; Lass-Flörl, C.

COVID-19 Associated Pulmonary

Aspergillosis: Diagnostic

Performance, Fungal Epidemiology and Antifungal Susceptibility. $J$

Fungi 2022, 8, 93. https://doi.org/

$10.3390 /$ jof 8020093

Academic Editor: Willem Melchers

Received: 13 December 2021

Accepted: 17 January 2022

Published: 18 January 2022

Publisher's Note: MDPI stays neutral with regard to jurisdictional claims in published maps and institutional affiliations.

Copyright: (C) 2022 by the authors. Licensee MDPI, Basel, Switzerland. This article is an open access article distributed under the terms and conditions of the Creative Commons Attribution (CC BY) license (https:// creativecommons.org/licenses/by/ $4.0 /)$.

\begin{abstract}
Coronavirus disease 2019 (COVID-19)-associated pulmonary aspergillosis (CAPA) raises concerns as to whether it contributes to an increased mortality. The incidence of CAPA varies widely within hospitals and countries, partly because of difficulties in obtaining a reliable diagnosis. We implemented a routine screening of respiratory specimens in COVID-19 ICU patients for Aspergillus species using culture and galactomannan (GM) detection from serum and/or bronchoalveolar lavages (BAL). Out of 329 ICU patients treated during March 2020 and April 2021, 23 (7\%) suffered from CAPA, 13 of probable, and 10 of possible. In the majority of cases, culture, microscopy, and GM testing were in accordance with CAPA definition. However, we saw that the current definitions underscore to pay attention for fungal microscopy and GM detection in BALs, categorizing definitive CAPA diagnosis based on culture positive samples only. The spectrum of Aspergillus species involved Aspergillus fumigatus, followed by Aspergillus flavus, Aspergillus niger, and Aspergillus nidulans. We noticed changes in fungal epidemiology, but antifungal resistance was not an issue in our cohort. The study highlights that the diagnosis and incidence of CAPA is influenced by the application of laboratory-based diagnostic tests. Culture positivity as a single microbiological marker for probable definitions may overestimate CAPA cases and thus may trigger unnecessary antifungal treatment.
\end{abstract}

Keywords: aspergillosis; COVID-19; coronavirus disease 2019 (COVID-19)-associated pulmonary aspergillosis (CAPA); antifungal susceptibility testing; fungal diagnosis

\section{Introduction}

Invasive aspergillosis is frequently recognized in immunocompromised hosts, such as transplant recipients and patients with hematologic malignancies, patients receiving long-term or high dose steroids or other immunosuppressant drugs [1]. Aspergillosis associated with severe influenza virus infection (influenza-associated aspergillosis, IAPA) has been increasingly detected during the 2009 influenza A (H1N1) pandemic [2]. A 7-year retrospective study from Belgium and the Netherlands reported $14 \%$ and $31 \%$ of immunocompetent and immunocompromised patients being affected [3], respectively. The outbreak 
of the current severe acute respiratory syndrome coronavirus 2 (SARS-CoV-2) pandemic led to an increase of intensive care patients with severe pulmonary disorders [4]. Thus, several reports of coronavirus disease 2019 (COVID-19)-associated pulmonary aspergillosis (CAPA) [5-7] have raised concerns that this superinfection contributes to an increased mortality $[8,9]$. However, cases of CAPA were found to vary widely between hospitals and countries, intensive care units (ICU) reported rates from 3\% to 33\% [10]. These differences might be partly caused by difficulties in obtaining a reliable diagnosis and the lack of a specific clinical presentation; radiological features are not distinctive and diagnostic bronchoscopy is less frequently used in COVID-19 patients due to the risk of infectious aerosols [5]. In addition, a low sensitivity for circulating galactomannan (GM) in serum complicates any diagnostic evaluation, and the detection of Aspergillus species (sp.) in upper respiratory specimens does not distinguish fungal colonization from infection $[5,10,11]$. ECMM/ISHAM set consensus criteria for research and clinical guidance for defining and managing CAPA [5]. Here, CAPA is defined as possible, probable, or proven, based on host factors (patient with COVID-19 and requiring ICU care), clinical factors, and mycological evidence. During the first wave of the pandemic in Austria, we observed a slight increase of culture positive specimens (Aspergillus sp.) in the diagnostic laboratory of the Institute of Hygiene and Medical Microbiology, Medical University of Innsbruck, Innsbruck, Austria (unpublished data). To improve patient management, a routine screening of respiratory specimens (COVID-19 ICU patients) for Aspergillus sp. using culture and GM assays from serum or bronchoalveolar lavages (BAL) was implemented. We aimed to explore and describe our experience in diagnosing CAPA according to the newly defined consensus diagnostic criteria.

\section{Materials and Methods}

\subsection{Collection of Respiratory Samples and Fungal Diagnostics}

Cases of CAPA were identified during March 2020-April 2021 at the Medical University Hospital of Innsbruck (approximately 1600 beds, one of the biggest hospitals in Austria) by review of microbiological and infectious disease consultant data, with approval of the institutional review board. An intensive diagnostic screening procedure for Aspergillus sp. was implemented for all SARS-CoV-2 positive ICU patients. This included the usage of an additional Sabouraud-Glucose-Agar (SAB) plate for all routinely taken respiratory specimens. The incubation was done at $37^{\circ} \mathrm{C}$ for 3 days; growth of Aspergillus sp. prompted species identification (MALTI-TOF MS) and the performance of GM detection (PlateliaAspergillus Test, Biorad, Vienna, Austria) in serum and/or respiratory fluids (tracheobronchial aspirates, BALs) and microscopy (Calcoflour white staining); screening independent fungal diagnostics were requested following the suspicion of fungal infections being present. The latter included GM detection from serum and/or BAL, and/or Aspergillus and panfungal PCR [12], microscopy, and culture. The standard of care clinical diagnostic procedures (e.g., chest radiograph or computer tomography scans (CT)) were routinely performed. Charts were reviewed to summarize demographic, clinical, and outcome data; cases were defined by CAPA criteria released in 2021 [5] by usage of pseudo-anonymized case report forms; another focus of interest was the epidemiology of Aspergillus sp. detected and the antifungal susceptibility profile against caspofungin, amphotericin B, voriconazole, posaconazole, isavuconazole, and micafungin. Susceptibility testing was performed using Etest ${ }^{\circledR}$ (BioMerieux, Marcy-l'Étoile, Paris, France), once growth of fungal culture was evident.

\subsection{CAPA Definitions}

The diagnosis of probable pulmonary CAPA requires a pulmonary infiltrate or nodules, preferably documented by chest $\mathrm{CT}$, or cavitating infiltrate (not attributed to another cause), or both, combined with mycological criteria [5]. The latter include positive microscopy in BAL (indicating molds), or culture positive BALs; serum GM index $>0.5$ or BAL GM index $\geq 1.0$ or $\geq 2$ Aspergillus PCR tests in plasma, serum, or whole blood; or a single positive 
Aspergillus PCR in BAL (cycle threshold $<36$ or in plasma, serum, or whole blood, and a single positive in BAL (any threshold cycle)) [5].

Possible pulmonary CAPA requires pulmonary infiltrate or nodules, preferably documented by chest $\mathrm{CT}$, or cavitating infiltrate (which is not attributed to another cause) in combination with mycological evidence (e.g., microscopy, culture, or galactomannan, alone or in combination) obtained by non-bronchoscopic lavage [5].

\section{Results}

Our retrospective case study included 329 ICU patients diagnosed with SARS-CoV-2 included in the COVID-19 ICU registry [13], 23 of these patients (7\%) revealed Aspergillus positive culture during hospitalization at the University Hospital Innsbruck, Innsbruck Austria. A total of 10 and 13 patients were classified to suffer from probable and possible CAPA. Microbiological details of culture, microscopy and GM testing are given in Tables 1 and 2. In total, the study cohort included 6 female and 17 male Aspergillus culture positive individuals, aged between 39 and 84 years (median $=63$ years), see Table 1 . Duration of ICU stay ranged from 1 to 15 weeks and mostly implicated invasive mechanical ventilation. Underlying risk factors were diabetes mellitus $(n=10)$, being a regular (ex-)smoker $(n=8)$, severe obesity $(n=6)$, and organ transplantation $(n=6)$. Further, patients suffered from asthma, chronic obstructive pulmonary diseases and malignancies (Table 1). The administration of corticosteroids was documented for most, but not all patients. COVID-19 treatment followed according to the Austrian ICU SARS-CoV-2 treatment recommendations [14]. Patients were tested positive for SARS-CoV-2 5 to 55 days (median, 12 days) before proof of Aspergillus by culture, see Figure 1. All patients received broad-spectrum antibiotics and showed pulmonary infiltrates on imaging at the time-point of positive Aspergillus culture, herewith fulfilling CAPA entry criteria [5]. Antifungals initiated were voriconazole, posaconazole, amphotericin B, and anidulafungin or caspofungin, for drug regiments see Table 1. Antifungal treatment was done according to clinical guidance management of CAPA [5]; treatment duration varied form patient to patient and was continued either until death or for three more weeks. In particular, single patients received various combinations of antifungals, four patients classified as possible CAPA did not receive any antifungal treatment because of possible CAPA, and one patient was under fluconazole treatment due to severe Candida colonization of the respiratory tract, see Tables 1 and 2. Fungal diagnostics were specifically requested for only three SARS-CoV-2 patients, see Table 2. Mortality was $67 \%$ and $42 \%$ for probable and possible CAPA.

Species involved were Aspergillus fumigatus (A. fumigatus) (22), Aspergillus flavus (A. flavus) (2), and one case each of Aspergillus nidulans (A. nidulans) and Aspergillus niger (A. niger). Minimal inhibitory concentrations (MIC) for caspofungin, amphotericin B, voriconazole, posaconazole, isavuconalzole, and micafungin are presented in Table 2; only wild type strains for A. fumigatus were detected, see Figure 2. 
Table 1. Clinical data of 23 CAPA patients, defined according to ECMM/ISHAM criteria.

\begin{tabular}{|c|c|c|c|c|c|c|c|c|c|c|c|}
\hline ID & Age (Y) & $\begin{array}{l}\text { Sex } \\
\text { (F/M) }\end{array}$ & $\begin{array}{c}\text { Reason for } \\
\text { Hospitalization }\end{array}$ & $\begin{array}{l}\text { ICU Stay } \\
\text { (Weeks) }\end{array}$ & $\begin{array}{c}\text { IV } \\
\text { (Weeks) }\end{array}$ & $\begin{array}{l}\text { Underlying Risk } \\
\text { Factors }\end{array}$ & $\begin{array}{c}\text { Cortisteroid } \\
\text { Treatment }\end{array}$ & $C F$ and $I$ & $\begin{array}{c}\text { Antifungal } \\
\text { Treatment }\end{array}$ & $\begin{array}{c}\text { Death within } 6 \text { Weeks } \\
\text { (Days after Culture } \\
\text { Positivity, Cause) }\end{array}$ & CAPA \\
\hline 1 & 73 & $\mathrm{~m}$ & COVID-19 & $3-4$ & $3-4$ & KTR, AVR & Yes & Yes & Ani & (4, COVID-19) & Probable \\
\hline 2 & 70 & $\mathrm{~m}$ & COVID-19 & $3-4$ & $\leq 2$ & none & Yes & Yes & & & Possible \\
\hline 3 & 20 & $\mathrm{~m}$ & COVID-19 & $>4$ & $>4$ & OB & Yes & Yes & Cas & & Probable \\
\hline 4 & 84 & $\mathrm{~m}$ & COVID-19 & $\leq 2$ & $\leq 2$ & $\mathrm{DM}, \mathrm{M}$ & Yes & Yes & & (6, Lung failure) & Probable \\
\hline 5 & 79 & $\mathrm{f}$ & COVID-19 & $>4$ & $>4$ & A & Yes & Yes & Amp & (35, COVID-19) & Possible \\
\hline 6 & 76 & $\mathrm{f}$ & COVID-19, SMI & $3-4$ & $\leq 2$ & S & & Yes & Amp & (3, Pneumonia) & Probable \\
\hline 7 & 77 & $\mathrm{f}$ & COVID-19 & $\leq 2$ & $\leq 2$ & $\mathrm{DM}, \mathrm{OB}$ & Yes & Yes & Amp & (7, COVID-19) & Probable \\
\hline 8 & 56 & $\mathrm{~m}$ & COVID-19 & $>4$ & $>4$ & COPD, DM, S, OB & Yes & Yes & Vor, Amp & & Possible \\
\hline 9 & 61 & $\mathrm{~m}$ & COVID-19 & $>4$ & $>4$ & none & & Yes & Vor, Pos & & Probable \\
\hline 10 & 50 & $\mathrm{~m}$ & COVID-19 & $\leq 2$ & $\leq 2$ & $\mathrm{DM}$ & Yes & Yes & Amp & & Possible \\
\hline 11 & 83 & $\mathrm{f}$ & COVID-19 & $\leq 2$ & $\leq 2$ & COPD, S, DM & Yes & Yes & & & Possible \\
\hline 12 & 39 & $\mathrm{f}$ & $\begin{array}{c}\text { COVID-19, } \\
\text { cholecystectomy }\end{array}$ & $\leq 2$ & $\leq 2$ & KTR, OFD1 & & Yes & Ani, Amp & (6, Sepsis with MOF) & Probable \\
\hline 13 & 60 & $\mathrm{~m}$ & COVID-19 & $>4$ & $>4$ & $\mathrm{OB}$ & Yes & Yes & & & Possible \\
\hline 14 & 59 & $\mathrm{~m}$ & UTI, COVID-19 & $>4$ & $>4$ & $\begin{array}{c}\text { DM, S, KTR, PTR, } \\
\text { ex-TBP }\end{array}$ & Yes & Yes & $\begin{array}{l}\text { Vor, Amp, } \\
\text { Ani }\end{array}$ & & Probable \\
\hline 16 & 58 & $\mathrm{~m}$ & $\begin{array}{l}\text { CP, sepsis, } \\
\text { COVID-19 }\end{array}$ & $>4$ & $3-4$ & DM, NTR & Yes & Yes & Vor & & Probable \\
\hline 17 & 82 & $\mathrm{~m}$ & COVID-19 & $\leq 2$ & $\leq 2$ & $\mathrm{DM}, \mathrm{S}$ & & Yes & Vor, Amp & $\begin{array}{c}\text { (5, MOF after } \\
\text { COVID-19) }\end{array}$ & Possible \\
\hline 18 & 55 & $\mathrm{~m}$ & COVID-19 & $3-4$ & $\leq 2$ & DM, OB & Yes & Yes & Vor, Amp & & Possible \\
\hline 19 & 74 & $\mathrm{f}$ & COVID-19 & $\leq 2$ & $\leq 2$ & COPD, DM, S & Yes & Yes & Flu & $\begin{array}{l}\text { (2, AKF after } \\
\text { COVID-19) }\end{array}$ & Possible \\
\hline 20 & 47 & $\mathrm{~m}$ & COVID-19 & $>4$ & $\leq 2$ & OB & Yes & Yes & Vor & & Possible \\
\hline 21 & 72 & $\mathrm{~m}$ & COVID-19 & $3-4$ & $3-4$ & M & Yes & Yes & Isa & (20, Lung failure) & Probable \\
\hline 22 & 75 & $\mathrm{~m}$ & COVID-19 & $3-4$ & $3-4$ & $S$ & & Yes & Vor & $(12$, Sepsis with MOF) & Possible \\
\hline 23 & 83 & $\mathrm{~m}$ & COVID-19 & $3-4$ & $\leq 2$ & $S$ & & Yes & & & Possible \\
\hline
\end{tabular}


Table 2. Microbiological data of 23 CAPA patients, defined according to ECMM/ISHAM criteria.

\begin{tabular}{|c|c|c|c|c|c|c|c|c|c|c|c|c|c|c|c|c|}
\hline \multirow[b]{2}{*}{ ID } & \multicolumn{2}{|c|}{ Culture } & \multicolumn{6}{|c|}{ Etest $\odot$ MICs $(\mathrm{mg} / \mathrm{L})$} & \multicolumn{2}{|c|}{ GM } & \multicolumn{2}{|c|}{ PCR } & \multicolumn{2}{|c|}{ CFW } & \multirow{2}{*}{$\begin{array}{c}\text { Fungal Diagnostics } \\
\text { Requested by } \\
\text { Clinician }\end{array}$} & \multirow[b]{2}{*}{ CAPA } \\
\hline & SM & Species & CAS & AMB & VOR & POS & ISA & MICA & SM & Index & SM & Species & SM & $\begin{array}{c}\text { Septate } \\
\text { Mycelium }\end{array}$ & & \\
\hline 1 & TS & $\begin{array}{c}\text { A. fumigatus } \\
\text { A. flavus }\end{array}$ & $\begin{array}{c}0.06 \\
0.008\end{array}$ & $\begin{array}{c}0.5 \\
8\end{array}$ & $\begin{array}{l}0.12 \\
0.12\end{array}$ & $\begin{array}{c}0.032 \\
0.12\end{array}$ & $\begin{array}{l}0.12 \\
0.12\end{array}$ & $\begin{array}{l}0.008 \\
0.002\end{array}$ & Serum & 2.59 & - & - & TS & Pos & & $\begin{array}{l}\text { Probable } \\
\text { Possible }\end{array}$ \\
\hline 2 & TS & $\begin{array}{l}\text { A. fumigatus } \\
\text { A. flavus }\end{array}$ & $\begin{array}{c}0.06 \\
0.016\end{array}$ & $\begin{array}{c}0.5 \\
4\end{array}$ & $\begin{array}{l}0.12 \\
0.12\end{array}$ & $\begin{array}{c}0.032 \\
0.12\end{array}$ & $\begin{array}{l}0.12 \\
0.12\end{array}$ & $\begin{array}{l}0.008 \\
0.002\end{array}$ & Serum & Neg & - & - & - & - & & $\begin{array}{l}\text { Probable } \\
\text { Probable }\end{array}$ \\
\hline 3 & BAL & A. fumigatus & 0.06 & 0.5 & 0.06 & 0.03 & 0.12 & 0.008 & Serum & Neg & BAL & $\mathrm{Neg}$ & BAL & $\mathrm{Neg}$ & & Possible \\
\hline 4 & TS & A. fumigatus & 0.12 & 0.5 & 0.12 & 0.06 & 0.12 & 0.008 & Serum & 0.63 & - & - & - & - & & Probable \\
\hline 6 & BAL & A. fumigatus & 0.06 & 0.25 & 0.06 & 0.008 & 0.12 & 0.008 & BAL & 3.51 & BAL & A. fumigatus & BAL & Pos & $\begin{array}{c}\text { Culture, GM, PCR, } \\
\text { CFW }\end{array}$ & Possible \\
\hline 7 & TS & A. fumigatus & 0.06 & 1 & 0.12 & 0.016 & 0.06 & 0.004 & Serum & 0.66 & - & - & - & - & & Probable \\
\hline 8 & TS & A. fumigatus & 0.06 & 0.25 & 0.12 & 0.032 & 0.12 & 0.008 & $\begin{array}{l}\text { Serum } \\
\text { BAL }\end{array}$ & Neg & - & - & BAL & $\mathrm{Neg}$ & & Possible \\
\hline 9 & BAL & A. fumigatus & 0.016 & 0.5 & 0.06 & 0.032 & 0.25 & 0.008 & BAL & Neg & BAL & $\mathrm{Neg}$ & BAL & Neg & Culture, CFW & Possible \\
\hline 10 & TS & A. fumigatus & 0.06 & 0.5 & 0.12 & 0.06 & 0.12 & 0.004 & Serum & $\mathrm{Neg}$ & - & - & - & - & & Probable \\
\hline 11 & SP & A. fumigatus & 0.12 & 0.25 & 0.12 & 0.032 & 0.06 & 0.008 & Serum & $\mathrm{Neg}$ & - & - & - & - & & Possible \\
\hline 12 & TS & A. fumigatus & 0.12 & 1 & 0.12 & 0.06 & 0.12 & 0.004 & BAL & 4.83 & $\begin{array}{l}\text { BAL } \\
\text { EDTA- } \\
\text { blood }\end{array}$ & $\begin{array}{l}\text { A. fumigatus } \\
\text { A. fumigatus }\end{array}$ & BAL & Pos & & $\begin{array}{l}\text { Probable } \\
\text { Possible }\end{array}$ \\
\hline 13 & TS & A. fumigatus & 0.25 & 0.5 & 0.12 & 0.06 & 0.12 & 0.004 & Serum & Neg & - & - & - & - & & Probable \\
\hline 14 & TS & $\begin{array}{l}\text { A. fumigatus } \\
\text { A. nidulans }\end{array}$ & $\begin{array}{l}0.032 \\
0.032\end{array}$ & $\begin{array}{c}0.5 \\
0.25\end{array}$ & $\begin{array}{l}0.12 \\
0.06\end{array}$ & $\begin{array}{c}0.032 \\
0.06\end{array}$ & $\begin{array}{c}0.25 \\
0.032\end{array}$ & $\begin{array}{l}0.002 \\
0.004\end{array}$ & BAL & Neg & $\begin{array}{l}\text { EDTA- } \\
\text { blood }\end{array}$ & A. fumigatus & BAL & Pos & & $\begin{array}{l}\text { Possible } \\
\text { Possible }\end{array}$ \\
\hline 15 & TS & A. fumigatus & 0.12 & 0.5 & 0.12 & 0.032 & 0.12 & 0.004 & Serum & Neg & - & - & BAL & $\mathrm{Neg}$ & & Possible \\
\hline 16 & BAL & A. fumigatus & 0.12 & 0.5 & 0.12 & 0.06 & 0.25 & 0.008 & BAL & 6.82 & BAL & A. fumigatus & BAL & Pos & & Possible \\
\hline 17 & TS & A. fumigatus & 0.12 & 1 & 0.06 & 0.032 & 0.12 & 0.002 & Serum & Neg & - & - & - & - & & Probable \\
\hline 18 & TS & A. fumigatus & 0.12 & 1 & 0.12 & 0.032 & 0.12 & 0.016 & Serum & $\mathrm{Neg}$ & - & - & - & - & & Possible \\
\hline 19 & TS & A. fumigatus & 0.032 & 0.5 & 0.12 & 0.06 & 0.25 & 0.002 & Serum & $\mathrm{Neg}$ & - & - & - & - & & Possible \\
\hline 20 & TS & A. fumigatus & 0.03 & 0.5 & 0.06 & 0.03 & 0.12 & 0.008 & Serum & $\mathrm{Neg}$ & - & - & BS & Neg & & Probable \\
\hline 21 & $\begin{array}{c}\text { TS } \\
\text { BAL }\end{array}$ & A. fumigatus & 0.06 & 0.5 & 0.12 & 0.06 & 0.12 & 0.016 & BAL & 6.69 & BAL & A. fumigatus & BAL & Pos & $\begin{array}{c}\text { Culture } \\
\text { Cult., GM, PCR, } \\
\text { CFW }\end{array}$ & $\begin{array}{l}\text { Possible } \\
\text { Probable }\end{array}$ \\
\hline 22 & TS & A. fumigatus & 0.06 & 0.5 & 0.12 & 0.06 & 0.12 & 0.002 & Serum & $\mathrm{Neg}$ & BS & $\mathrm{Neg}$ & BS & Neg & & Probable \\
\hline 23 & SP & A. niger & 0.06 & 2 & 1 & 0.5 & 0.25 & 0.004 & Serum & Neg & - & - & - & - & & Possible \\
\hline
\end{tabular}




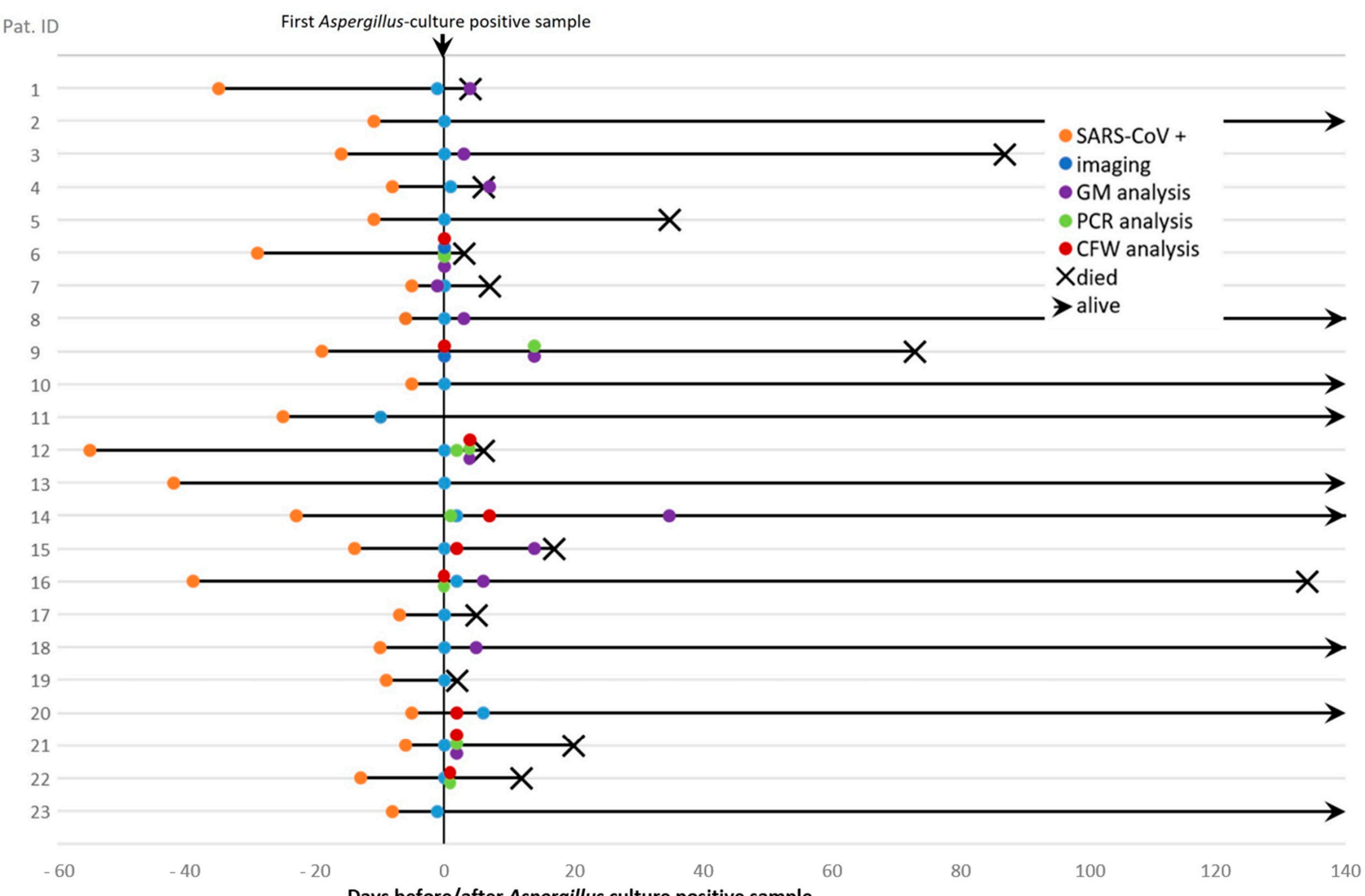

Figure 1. Timeline of patient cases calculated from the day of the first Aspergillus positive sample. 

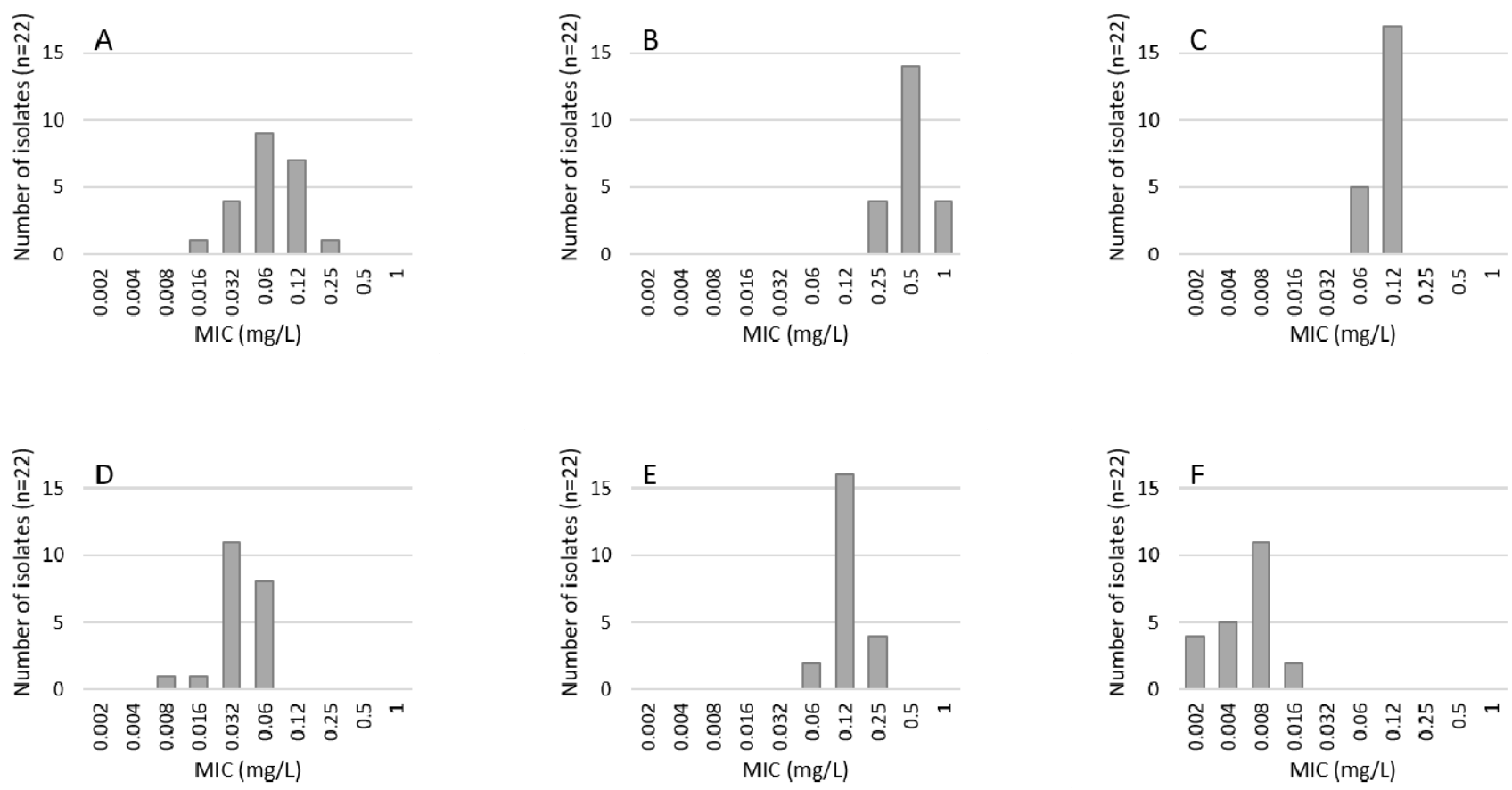

Figure 2. Distribution of minimal inhibitory concentrations (MIC) of (A) caspofungin, (B) amphotericinB, (C) voriconazol, (D) posaconazol, (E) isavuconazol, and (F) micafungin determined by Etest ${ }^{\circledR}$ of 22 A. fumigatus isolates from respiratory samples of COVID patients.

\section{Discussion}

In this study, using the CAPA definition criteria proposed by Koehler et al. [5], we diagnosed 10 and 13 probable and possible cases, resulting in an incidence of $7 \%$ for CAPA in COVID-19 ICU patients in the University Hospital Innsbruck, Innsbruck, Austria. Interestingly, targeted fungal diagnostic tests were only requested for three ICU patients, suggesting that there was no clinical suspicion of an Aspergillus-related infection in the remaining 20 SARS-CoV-2 infected individuals. This highlights that the diagnosis and incidence of CAPA are strongly influenced by the application of laboratory-based diagnostic tests.

In addition, we underline difficulties in the assessment if culture positivity is equated with positive microscopy for probable definitions. A deeper analysis supports the differentiation between culture and microscopy reports, at least in SARS-CoV-2 ICU patients; relying on culture positivity without subsequent additional diagnostic work up may overestimate CAPA cases. We categorized 10 probable cases of CAPA, supported by either culture positive BAL, GM positive BAL/serum, or both (plus clinical factors being present), see Table 2. In most cases, culture microscopy and GM testing were in accordance. However, two patients (ID 3 and 9) with culture positive BAL had negative microscopy as well as negative GM tests in serum and BAL, respectively. GM detection in BAL is a valid test to confirm or rule out pulmonary aspergillosis with a sensitivity and specificity of both approximately $90 \%$ using an optical density cut-off of $\geq 1$ in neutropenic patients [1]. It is well known that serum GM testing in SARS-CoV-2 patients is less accurate and that negative serum GM tests do not fully exclude an invasive fungal infection [5,15]. Apart from that, we observed that only patients with BAL positive microscopy presented with positive serum GM, suggesting a strong potential of microscopy in CAPA diagnosis. These patients could indeed represent "invasive" CAPA cases. Based on our results, we raise the question whether BAL culture positive but microscopic and GM negative cases suffer from possible rather than probable CAPA. We recommend a combination of fungal microscopy and GM testing in Aspergillus culture positive BALs for definitive diagnosis, being aware of the limited number of patients investigated. Another two patients (ID 4 and 7) had Aspergillus positive tracheal-secretions and positive GM borderline values (serum GM: 0.6) and hence 
were classified as probable CAPA cases; from a clinical point of view these patients had an infaust prognosis. Multiple serum GM testing is recommended to confirm or exclude the GM cut-off being exceeded or not. In general, culture positive tracheal-secretions and sputa led to possible CAPA definitions in our study population. The application of GM in serum was helpful for clinical decision making, as screening was negative in all cases. Based on clinical presentations, clinicians judged these patients as colonized rather than infected. Three possible CAPA cases underwent BAL, but microscopy and GM remained negative throughout hospitalization. Cut-off values for serum GM and BAL GM need specification for SARS-CoV-2 patients.

Mortality was high in patients with probable CAPA (67\%) and possible CAPA (42\%). These data are in agreement with several other studies [16,17] and underline the difficulties in the management of COVID-19 and superinfections in severe/critically ill patients. Demographic data and comorbidities were typical in our cohort and are in-line with other reports [5].

The spectrum of Aspergillus sp. involved was surprising for us as historically $30 \%$ of patients suffer from Aspergillus terreus (A. terreus) infection/colonization in Tyrol [18]. In this SARS-CoV-2 cohort, no single case of $A$. terreus was identified, instead $A$. fumigatus, followed by $A$. flavus, $A$. niger, and $A$. nidulans were detected. This is a rather unusual fungal epidemiology for the state Tyrol, Austria [19]. One reason could be that the study was restricted to the Innsbruck University Hospital, while the highest $A$. terreus incidences are found in the lower parts of Tyrol [20]. Otherwise, A. fumigatus is the most common species causing co-infections in COVID-19 patients [5]. The detection of $A$. flavus and A. niger from the upper respiratory tract secretions supports colonization rather than pulmonary infection [12].

Using Etest $($, we did not detect azole resistance or other non-wildtype strains in A. fumigatus. A. niger and A. flavus showed higher MICs for amphotericin B and were above the EUCAST epidemiological cut offs (ECOFFs) of 4 and $0.5 \mathrm{mg} / \mathrm{L}$, respectively [21]. This finding is not unusual as Gheith et al. (2014) found 67\% of A. flavus to be above the ECOFFs for amphotericin B [22]. In addition, Taghizadeh-Armaki et al. (2017) report of a reduced susceptibility of $A$. flavus to amphotericin B [23]. Importantly, for $A$. niger, the ECOFF definition by EUCAST is still tentative [21] and the ECOFF by CLSI is $2 \mathrm{mg} / \mathrm{L}$ [24]. The recommended first-line therapy for CAPA is voriconazole or isavuconazole [5], azole resistance was not detected and clinical breakpoints for amphotericin B are currently under investigation. Others, however, report from the recovery of azole-resistant strains in COVID-19 ICU patients [25].

We are aware that our study suffers from several limitations such as a low number of BAL positive culture patients, retrospective nature, and only few patients with probable CAPA. Whether any Aspergillus colonization (surrogate marker) requires antifungal treatment needs further clinical evaluation.

\section{Conclusions}

The implementation of an additional SAB agar plate for respiratory tract secretions of SARS-CoV-2 patients in the routine led to an increase of Aspergillus positive cultures. In general, fungal reports supported a definitive CAPA diagnosis when culture, microscopy, and GM testing were in accordance. However, we emphasize that we should have paid more attention to microscopy and GM detection in BALs before categorizing definitive CAPA diagnosis; culture positivity as a single microbiological marker for probable definitions may overestimate CAPA cases. The shift from A. terreus to A. fumigatus in SARS-CoV-2 patients displayed a changing face of fungal epidemiology in the state of Tyrol, Austria, whereas antifungal resistance in vitro was not an issue.

Author Contributions: Conceptualization, C.L.-F.; methodology, C.L.-F.; validation, N.L. and C.L.-F.; formal analysis, N.L.; investigation, E.S.; resources, C.L.-F.; data curation, N.L., C.T., D.Ö., M.J., T.M., R.A., W.P. and R.B.; writing—original draft preparation, N.L. and C.L.-F.; writing-review and editing, N.L., C.T., D.Ö., M.J., T.M., R.A., E.S., W.P., R.B. and C.L.-F.; visualization, N.L.; supervision, 
C.L.-F.; project administration, N.L.; funding acquisition, C.L.-F. All authors have read and agreed to the published version of the manuscript.

Funding: This research was funded by W1253-B24 doctoral program HOROS (Austrian Science Fund) and Christian Doppler Laboratory for Invasive Fungal Infections (C.L.-F.).

Institutional Review Board Statement: The study was conducted according to the guidelines of the Declaration of Helsinki, and approved by the Institutional Ethics Committee of the Medical University of Innsbruck (EK Nr: 1150/2021, approved on 7 June 2021).

Informed Consent Statement: Patient consent was not necessary due to the retrospective nature of this study.

Data Availability Statement: Data will be made available by the corresponding author on request as far as data protection of the patients can be warranted.

Acknowledgments: We thanks the Open Access Funding by the Austrian Science Fund (FWF).

Conflicts of Interest: The authors declare no conflict of interest.

\section{References}

1. Ullmann, A.J.; Aguado, J.M.; Arikan-Akdagli, S.; Denning, D.W.; Groll, A.H.; Lagrou, K.; Lass-Flörl, C.; Lewis, R.E.; Munoz, P.; Verweij, P.E.; et al. Diagnosis and management of Aspergillus diseases: Executive summary of the 2017 ESCMID-ECMM-ERS guideline. Clin. Microbiol. Infect. 2018, 24, E1-E38. [CrossRef] [PubMed]

2. Verweij, P.E.; Rijnders, B.J.A.; Bruggemann, R.J.M.; Azoulay, E.; Bassetti, M.; Blot, S.; Calandra, T.; Clancy, C.J.; Cornely, O.A.; Chiller, T.; et al. Review of influenza-associated pulmonary aspergillosis in ICU patients and proposal for a case definition: An expert opinion. Intens. Care Med. 2020, 46, 1524-1535. [CrossRef]

3. Schauwvlieghe, A.; Rijnders, B.J.A.; Philips, N.; Verwijs, R.; Vanderbeke, L.; Van Tienen, C.; Lagrou, K.; Verweij, P.E.; Van de Veerdonk, F.L.; Gommers, D.; et al. Invasive aspergillosis in patients admitted to the intensive care unit with severe influenza: A retrospective cohort study. Lancet Respir. Med. 2018, 6, 782-792. [CrossRef]

4. Lai, C.C.; Yu, W.L. COVID-19 associated with pulmonary aspergillosis: A literature review. J. Microbiol. Immunol. Infect. 2021, 54, 46-53. [CrossRef]

5. Koehler, P.; Bassetti, M.; Chakrabarti, A.; Chen, S.C.A.; Colombo, A.L.; Hoenigl, M.; Klimko, N.; Lass-Florl, C.; Oladele, R.O.; Vinh, D.C.; et al. Defining and managing COVID-19-associated pulmonary aspergillosis: The 2020 ECMM/ISHAM consensus criteria for research and clinical guidance. Lancet Infect. Dis. 2021, 21, e149-e162. [CrossRef]

6. $\quad$ Prattes, J.; Valentin, T.; Hoenigl, M.; Talakic, E.; Reisinger, A.C.; Eller, P. Invasive pulmonary aspergillosis complicating COVID-19 in the ICU-A case report. Med. Mycol. Case Rep. 2021, 31, 2-5. [CrossRef] [PubMed]

7. Prattes, J.; Wauters, J.; Giacobbe, D.R.; Salmanton-Garcia, J.; Maertens, J.; Bourgeois, M.; Reynders, M.; Rutsaert, L.; Van Regenmortel, N.; Lormans, P.; et al. Risk factors and outcome of pulmonary aspergillosis in critically ill coronavirus disease 2019 patients-a multinational observational study by the European Confederation of Medical Mycology. Clin. Microbiol. Infect. 2021. [CrossRef]

8. Verweij, P.E.; Bruggemann, R.J.M.; Azoulay, E.; Bassetti, M.; Blot, S.; Buil, J.B.; Calandra, T.; Chiller, T.; Clancy, C.J.; Cornely, O.A.; et al. Taskforce report on the diagnosis and clinical management of COVID-19 associated pulmonary aspergillosis. Intensive Care Med. 2021, 47, 819-834. [CrossRef] [PubMed]

9. $\quad$ Bartoletti, M.; Pascale, R.; Cricca, M.; Rinaldi, M.; Maccaro, A.; Bussini, L.; Fornaro, G.; Tonetti, T.; Pizzilli, G.; Francalanci, E.; et al. Epidemiology of invasive pulmonary aspergillosis among COVID-19 intubated patients: A prospective study. Clin. Infect. Dis. 2020, 73, e3606-e3614. [CrossRef] [PubMed]

10. Arastehfar, A.; Carvalho, A.; van de Veerdonk, F.L.; Jenks, J.D.; Koehler, P.; Krause, R.; Cornely, O.A.; Perlin, D.S.; Lass-Florl, C.; Hoenigl, M. COVID-19 associated pulmonary aspergillosis (CAPA)-from immunology to treatment. J. Fungi 2020, 6, 91. [CrossRef]

11. Lass-Flörl, C.; Samardzic, E.; Knoll, M. Serology anno 2021-fungal infections: From invasive to chronic. Clin. Microbiol. Infect. 2021, 27, 1230-1241. [CrossRef] [PubMed]

12. Lass-Flörl, C. How to make a fast diagnosis in invasive aspergillosis. Med. Mycol. 2019, 57, S155-S160. [CrossRef] [PubMed]

13. Mayerhöfer, T.; Klein, S.J.; Peer, A.; Perschinka, F.; Lehner, G.F.; Hasslacher, J.; Bellmann, R.; Gasteiger, L.; Mittermayr, M.; Eschertzhuber, S.; et al. Changes in characteristics and outcomes of critically ill COVID-19 patients in Tyrol (Austria) over 1 year. Wien. Klin. Wochenschr. 2021, 133, 1237-1247. [CrossRef] [PubMed]

14. Köstenberger, M.; Hasibeder, W.; Dankl, D.; Germann, R.; Hörmann, C.; Joannidis, M.; Markstaller, K.; Müller-Muttonen, S.O.; Neuwersch-Sommeregger, S.; Schaden, E.; et al. SARS-CoV-2: Recommendations for treatment in intensive care medicine. Wien. Klin. Wochenschr. 2020, 132, 664-670. [CrossRef] [PubMed]

15. Lahmer, T.; Kriescher, S.; Herner, A.; Rothe, K.; Spinner, C.D.; Schneider, J.; Mayer, U.; Neuenhahn, M.; Hoffmann, D.; Geisler, F.; et al. Invasive pulmonary aspergillosis in critically ill patients with severe COVID-19 pneumonia: Results from the prospective AspCOVID-19 study. PLoS ONE 2021, 16, e0238825. [CrossRef]

16. Marr, K.A.; Platt, A.; Tornheim, J.A.; Zhang, S.X.; Datta, K.; Cardozo, C.; Garcia-Vidal, C. Aspergillosis complicating severe coronavirus disease. Emerg. Infect. Dis. 2021, 27, 202896. [CrossRef] [PubMed] 
17. Fekkar, A.; Neofytos, D.; Nguyen, M.H.; Clancy, C.J.; Kontoyiannis, D.P.; Lamoth, F. COVID-19-associated pulmonary aspergillosis (CAPA): How big a problem is it? Clin. Microbiol. Infect. 2021, 27, 1376-1378. [CrossRef]

18. Lass-Florl, C.; Dietl, A.M.; Kontoyiannis, D.P.; Brock, M. Aspergillus terreus species complex. Clin. Microbiol. Rev. 2021, 34, e0031120. [CrossRef] [PubMed]

19. Lackner, M.; Coassin, S.; Haun, M.; Binder, U.; Kronenberg, F.; Haas, H.; Jank, M.; Maurer, E.; Meis, J.F.; Hagen, F.; et al. Geographically predominant genotypes of Aspergillus terreus species complex in Austria: S microsatellite typing study. Clin. Microbiol. Infect. 2016, 22, 270-276. [CrossRef]

20. Dietl, M.; Vahedi-Shahandashti, R.; Kandelbauer, C.; Kraak, B.; Lackner, M.; Houbraken, J.; Lass-Flörl, C. The environmental spread of Aspergillus terreus in Tyrol, Austria. Microorganisms 2021, 9, 539. [CrossRef] [PubMed]

21. European Committee on Antimicrobial Susceptibility Testing. Overview of Antifungal ECOFFs and Clinical Breakpoints for Yeasts, Moulds and Dermatophytes Using the EUCAST E.Def 7.3, E.Def 9.3 and E.Def 11.0 procedures: Version 2, 2020. Available online: https:/ / www.eucast.org/astoffungi/clinicalbreakpointsforantifungals/ (accessed on 14 November 2021).

22. Gheith, S.; Saghrouni, F.; Bannour, W.; Ben Youssef, Y.; Khelif, A.; Normand, A.C.; Piarroux, R.; Ben Said, M.; Njah, M.; Ranque, S. In vitro susceptibility to amphotericin B, itraconazole, voriconazole, posaconazole and caspofungin of Aspergillus spp. isolated from patients with haematological malignancies in Tunisia. Springerplus 2014, 3, 19. [CrossRef] [PubMed]

23. Taghizadeh-Armaki, M.; Hedayati, M.T.; Ansari, S.; Omran, S.M.; Saber, S.; Rafati, H.; Zoll, J.; van der Lee, H.A.; Melchers, W.J.G.; Verweij, P.E.; et al. Genetic diversity and in vitro antifungal susceptibility of 200 clinical and environmental Aspergillus flavus isolates. Antimicrob. Agents Chemother. 2017, 61, e00004-17. [CrossRef]

24. Clinical and Laboratory Standards Institute. Epidemiological Cutoff Values for Antifungal Susceptibility Testing, 2nd ed.; Clinical and Laboratory Standards Institute: Wayne, PA, USA, 2018; Available online: https://clsi.org/standards/products/microbiology/ documents/m59/ (accessed on 14 November 2021).

25. Ghelfenstein-Ferreira, T.; Saade, A.; Alanio, A.; Bretagne, S.; Araujo de Castro, R.; Hamane, S.; Azoulay, E.; Bredin, S.; Delliere, S. Recovery of a triazole-resistant Aspergillus fumigatus in respiratory specimen of COVID-19 patient in ICU-A case report. Med. Mycol. Case Rep. 2021, 31, 15-18. [CrossRef] 